\title{
Failure Analysis of Bolt of Rear Mounting Trunion of an Aero-Engine: A Case of Bending Induced Chevron Pattern as well as Fatigue Failure on the Same Fracture Surface
}

\author{
Mrityunjoy Hazra and Ashok Kumar Singh
}

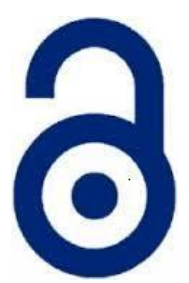

\author{
Received: 09 October 2020 \\ Accepted: 27 January 2021 \\ Published: 30 January 2021 \\ Publisher: Deer Hill Publications \\ (c) 2021 The Author(s) \\ Creative Commons: CC BY 4.0
}

\begin{abstract}
Present work describes the failure investigation of failed bolt of starboard rear mounting trunion of an aero-engine. Multiple fracture initiation points are noticed. This is a classic case of a single bending type of load initiating reversed bending fatigue as well as chevron pattern on the same fracture surface. Visually observed bending phenomenon supports the each type of failure mode. More interestingly, point of initiation of fast as well as the reversed bending fatigue failure is the same, although those two events have been found to be separate phenomena. It has been established that two different fatigue crack fronts, typical of reversed bending fatigue phenomenon propagated towards each other to make half of the cross-section fractured, while the another half failed by chevron patterned fast fracture. In this, the fast fracture of one half has preceded the reversed bending fatigue fracture of the other half, although the former is not responsible for happening of the later. Modes of fracture and factors influencing have been established in this article with emphasis on circumstantial evidence involving background information and visual examination, supported often by the open literature. Presence of cadmium (Cd) and its possible source, residence time and relative presence on differently fractured surfaces have offered important clues on establishing the sequence and relative inter-dependence of the said two fracture types. Presence of cadmium on the fracture surfaces, multiple crack initiation sites and numerous well-revealed secondary cracks on Branson cleaned fracture surface indicate that the cracks pre-existed on the material even before the cadmium plating and manifestation of chevron pattern is its extreme revelation. This pre-existing chevron pattern primarily aggravated the present failure through bending fatigue phenomenon in the later stages. Low alloy steel (ASTM grade 16) with presently used hardness (340 HV) level does not seem to suit the present application, as it is clear from its extreme brittleness as manifested by pre-existing cracks.
\end{abstract}

Key words: Bolt fracture, chevron pattern, bending fatigue, cadmium plating, low alloy steel.

\section{INTRODUCTION}

Bolts of starboard rear mounting trunion of aero-engine are generally made by low alloy steel. These are used in hardened and tempered condition wherein the material can be employed to withstand high strength at room / elevated temperatures with different loading conditions [1-3]. These bolts quite often fail by environmental induced embrittlements such as hydrogen embrittlement, stress corrosion cracking etc. Present work is thus concerned with the failure investigation of the bolt of starboard rear mounting trunion of an aero-engine. The failed parts of the broken bolt were received for failure investigation.

\section{EXPERIMENTAL PROCEDURE}

The as-received failed parts were at first visually observed with the help of naked eye and magnifying glass. Photographs were taken in as-received condition from various orientations and preserved for future reference during the course of analysis. Stereo microscopic images of the fracture surfaces were taken afterwards. Fracture surfaces from the as-received components were extracted delicately without damaging the same for further in-depth

Mrityunjoy Hazra $₫$ and Ashok Kumar Singh

Defence Metallurgical Research Laboratory (DMRL)

P.O. Kanchanbagh, Hyderabad 500 058, India

E-mail: mhazra@dmrl.drdo.in

Reference: Hazra, M. and Singh, A.K. (2021). Failure Analysis of Bolt of Rear Mounting Trunion of an Aero-Engine: A Case of Bending Induced Chevron Pattern as well as Fatigue Failure on the Same Fracture Surface. International Journal of Engineering Materials and Manufacture, 6(1), 34-42. 
examination under scanning electron microscope (SEM) equipped with electron dispersive spectroscopy (EDS). The fracture surfaces were examined under SEM after cleaning with acetone in an ultrasonic cleaner. Subsequently, the failed surfaces were also cleaned in ultrasonic cleaner using Branson liquid for removing oxide layers from the surface and to obtain representative fracture features. After the SEM examination was over, representative cross-sectional sample extraction from failed parts was carried out for metallographic (optical and scanning electron microscopic) studies. Examination was carried out in both un-etched and etched conditions. 3\% nital was used as etchant. Bulk compositional analysis of the samples was carried out by EDS analysis. Carbon, sulphur and hydrogen were analyzed by dry combustion technique. Vickers hardness readings at $20 \mathrm{~kg}$ load were taken on metallographically polished samples.

\section{RESULTS}

\subsection{Visual Examination}

The photographs (at various orientations) of failed parts in as-received condition are shown in Fig. 1. Marked pieces 1, 2 and 3 represent undamaged nut, bent and failed shank portion of the failed bolt along with failed and detached bolt head parts, respectively. Bending is vividly revealed in bolt shank part (Fig. 1 (a, d-f)).

\subsection{Fractography}

Stereo microscopic images of the shank fracture surface are displayed in Fig. 2. As-received surface is shown in Fig. 2a, while Fig. 2 (b-e) represents Branson cleaned surface. Various illuminating conditions and light intensities have been used with the fracture surfaces shown in Fig. 2 (b-e) as deemed appropriate to reveal fracture features. Points $A$ and $B$ appear to be two important fracture junctions with respect to initiation of the fracture surface under fatigue loading. Point B initiates another crack front distinguished by typical Chevron pattern. Arrows in Fig. 2 (b and d) indicate the propagation directions of the cracks.
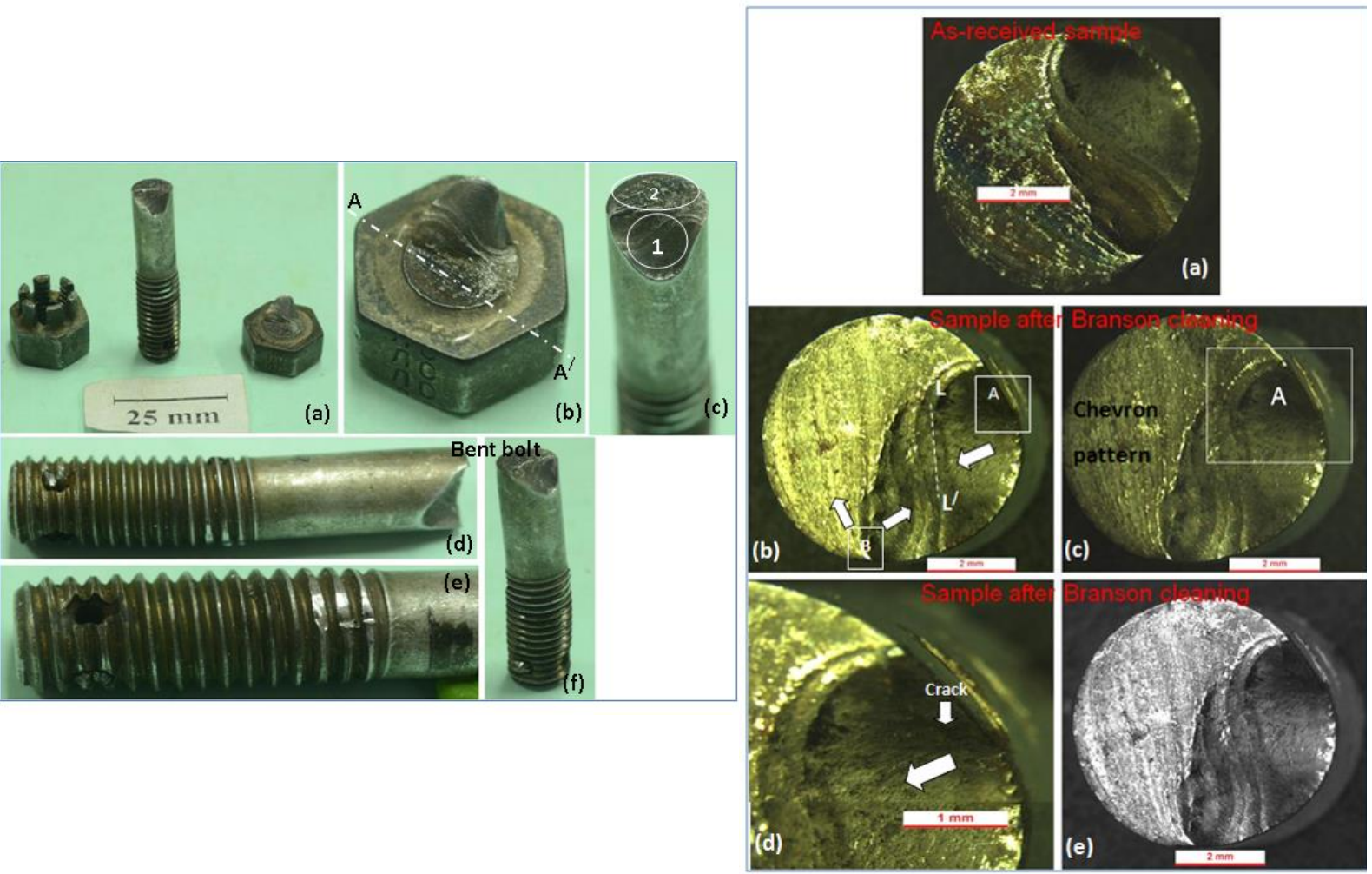

Fig.1: Photographs of as-received failed components.

Figure 2: Stereo microscopic images of failed bolt shank part in various illuminating and cleaning conditions: (a) acetone and (b-e) Branson cleaned conditions. 
SEM images of the shank fracture surface after acetone cleaning is exhibited in Fig. 3, as taken from top of the fracture surface. Right side plain region of the surface of Fig. 3a corresponds to the region 1 in Fig. 1, while the remaining rough region beside that one is region 2 in Fig. 1. Extensive rubbing has been noticed in both the regions (Fig. 3(c and d)). Quasi-cleavage fracture has been observed in region 2. Cadmium has been found to exist in major area of region 2 (Fig. 3 ( $a$ and b)). This has been confirmed by the EDS analysis (Fig. 4).

The fracture surfaces of bolt head are displayed in Fig. 5. Magnified image of region A (region B in Fig. 2) is displayed in Fig. 5b. Localized notch and few cracks seem to have been present along the periphery in this region. Crack marked in Fig. $5 \mathrm{~b}$ is basically the same location of the bolt shank part as is the location A in Fig. $2 \mathrm{~b}$. However, no corrosion pits and / or corrosion debris is found. Rough region B displays the presence of cadmium (white patches in Figs. $5 \mathrm{c}$ and 6), similar to that observed on the mating bolt shank fracture surface (Figs. 3 ( $a$ and b) and 4).

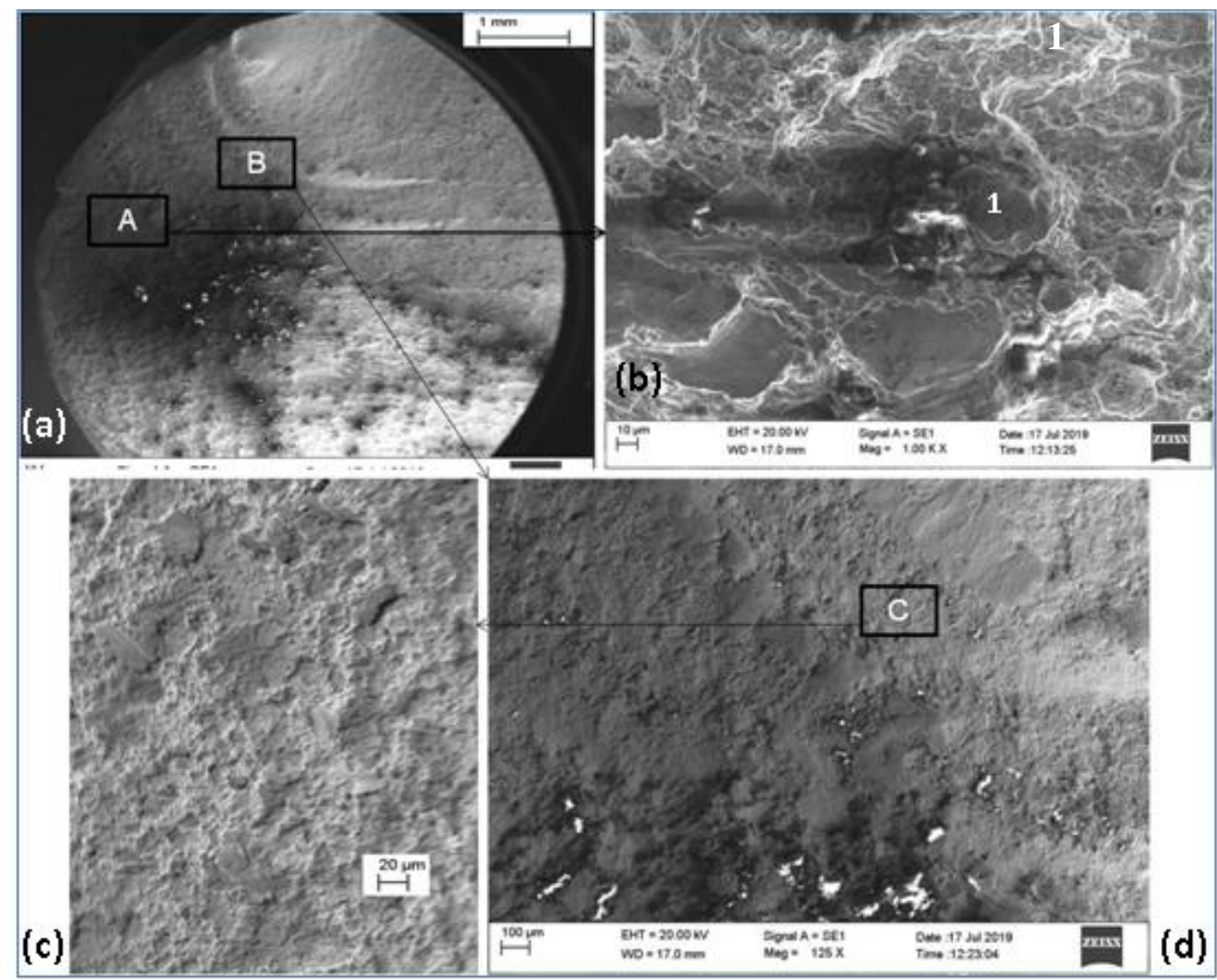

Fig. 3: SEM fractographs of failed bolt shank in acetone cleaned condition

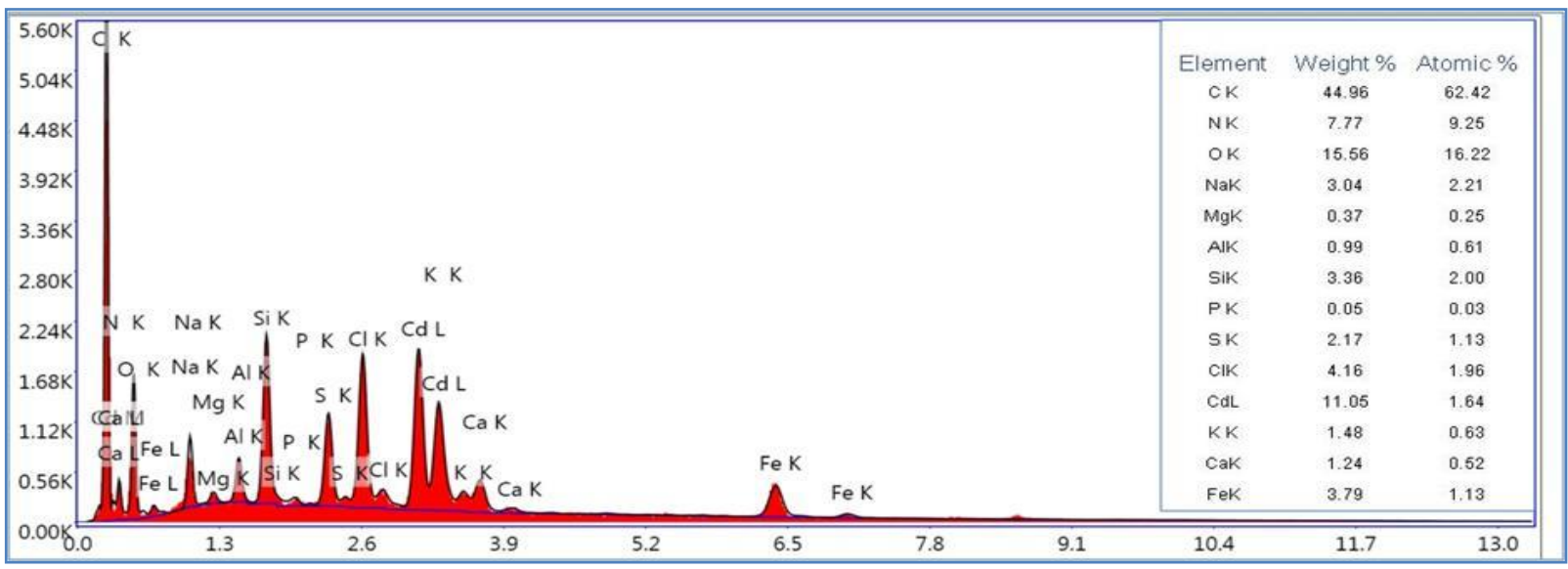

Fig. 4: EDS pattern taken from the point 1 in Fig. 3. 


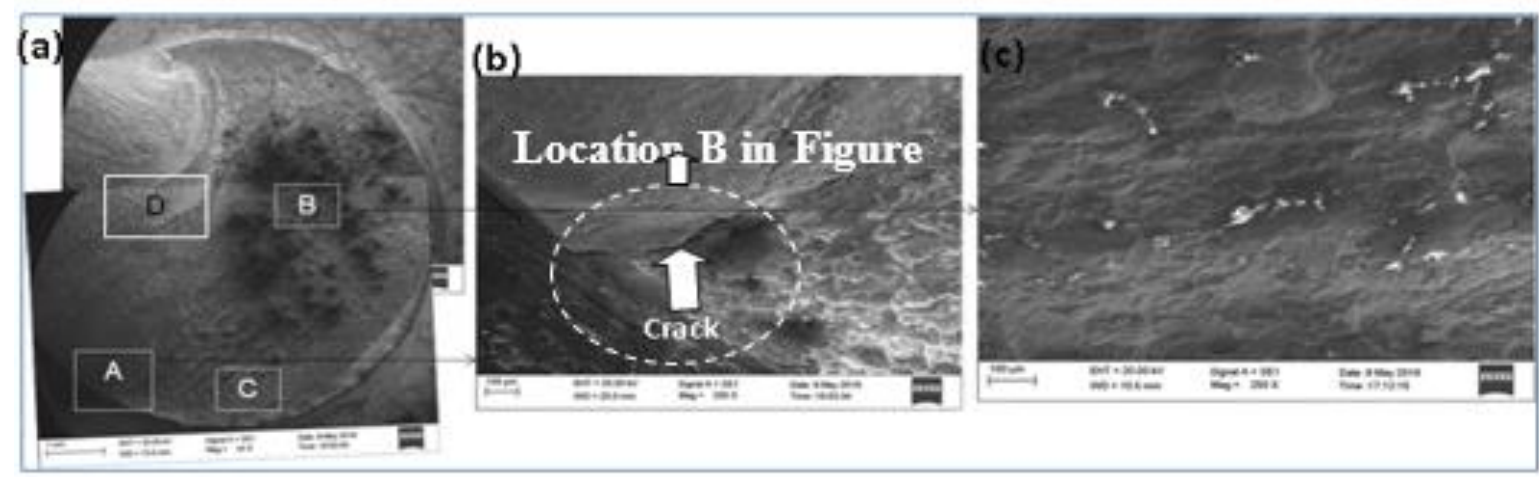

Fig. 5: SEM fractographs of failed bolt head in acetone cleaned condition.

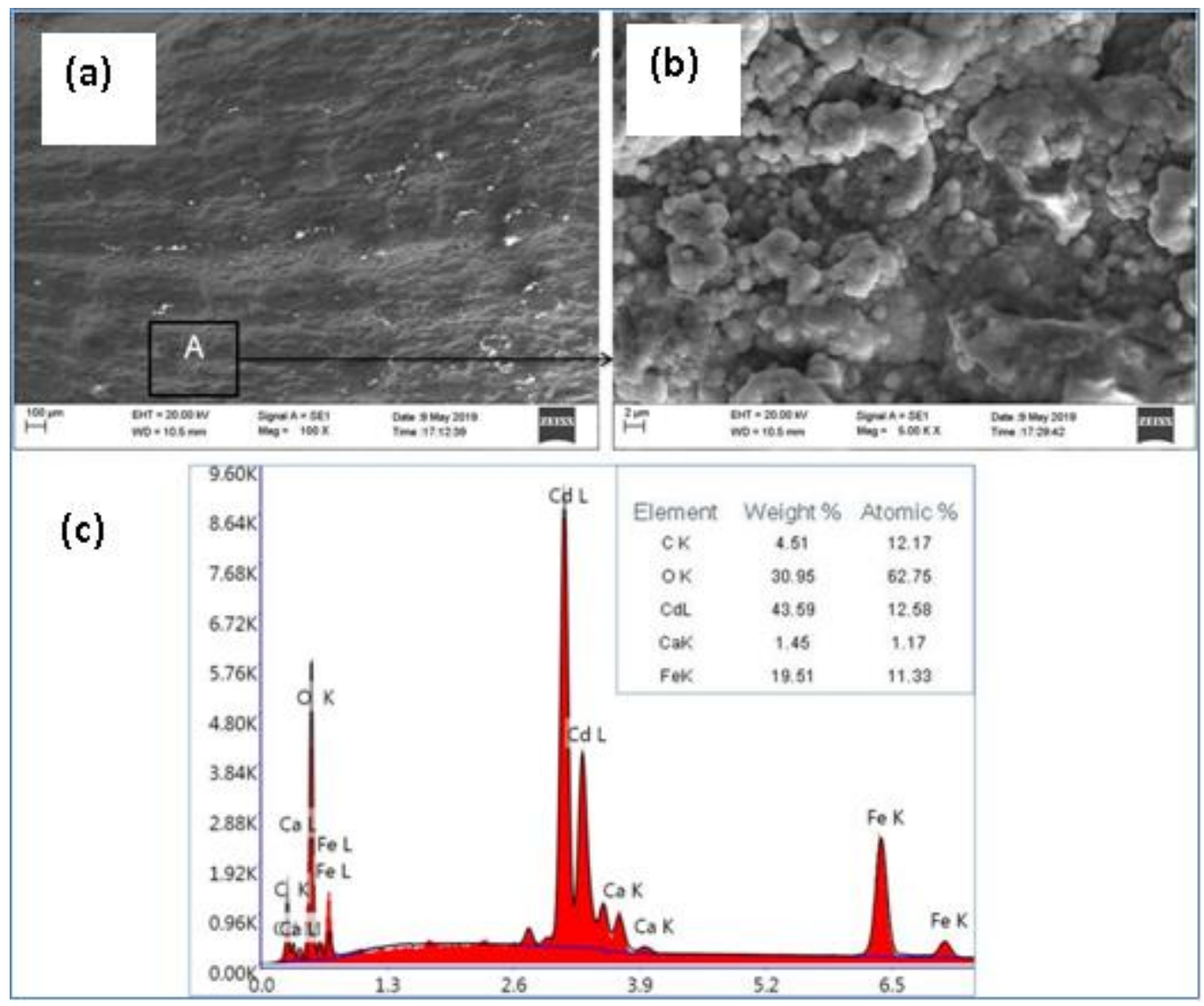

Fig. 6: High magnification images of region $C$ (in Fig. 5a) showing presence of tiny cadmium particles, (b) high magnification image of the region A (marked in (a)) and (c) EDS pattern taken from tiny particles.

High magnification image of apparently clean region $C$ is presented in Fig. 6. Cadmium has been found to exist as tiny round particles even here. Fig. 7 displays high magnification image of a typical area of region D in Fig. 5 (region 1 in Fig. 1c). The EDS patterns are taken from various locations (1, 2, 3 and 4) and results are presented in Fig. 7. Cadmium has been found even in some areas of this region (especially location 1), while few other areas reveal the presence of corrosion debris (locations 3, 4 in form of Fe-O) and base material (location 2). 


\subsection{Metallography}

Metallographic sample was extracted from the fracture surface along plane A-A' in Fig. 1b. Un-etched optical microstructure of the sample shows the presence of cadmium coating, as confirmed by corresponding EDS pattern (Fig. 9a). Fig. 9b exhibits the presence of oxides and few sulphide stringers. A well revealed crack and many other small cracks are found in the sample (Fig. 9c).

The microstructures in etched condition are presented in Fig. 10. This clearly reflects the presence of banding (Fig. 10a). High magnification micrographs show the presence of tempered martensite. Many small cracks and crack like appearances are observed in the microstructure at periphery of fracture surface.

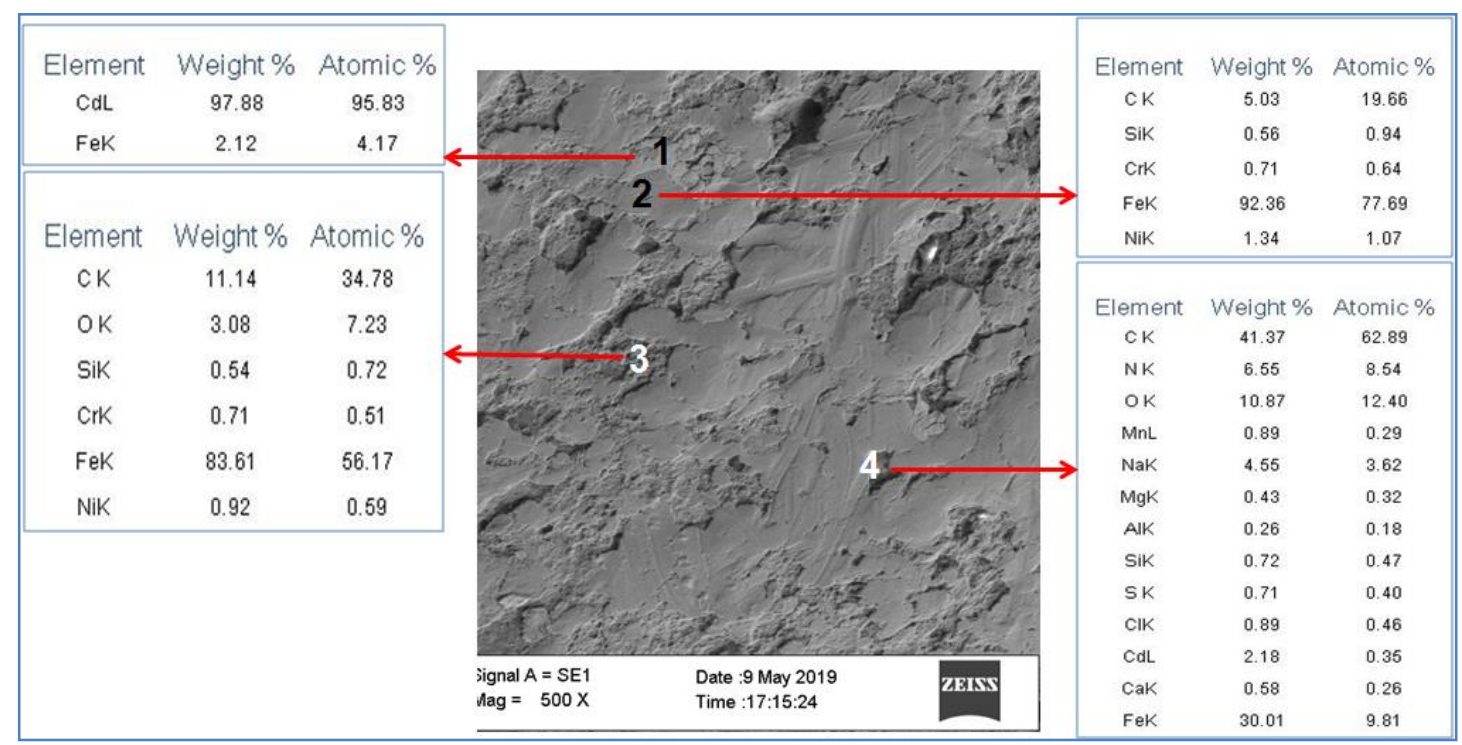

Fig. 7: High magnification images of region D in Fig. 5a and (b-e) EDS data taken from the locations 1, 2, 3 and 4. The fracture surface of failed bolt shank is shown in Fig. 8 after Branson cleaning. Cadmium is not found in region 2 after this cleaning. This reveals the presence of micro-cracks throughout the rubbed fracture surface.

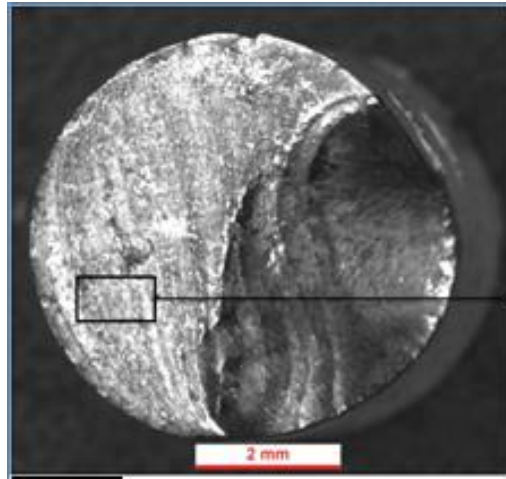

(a)

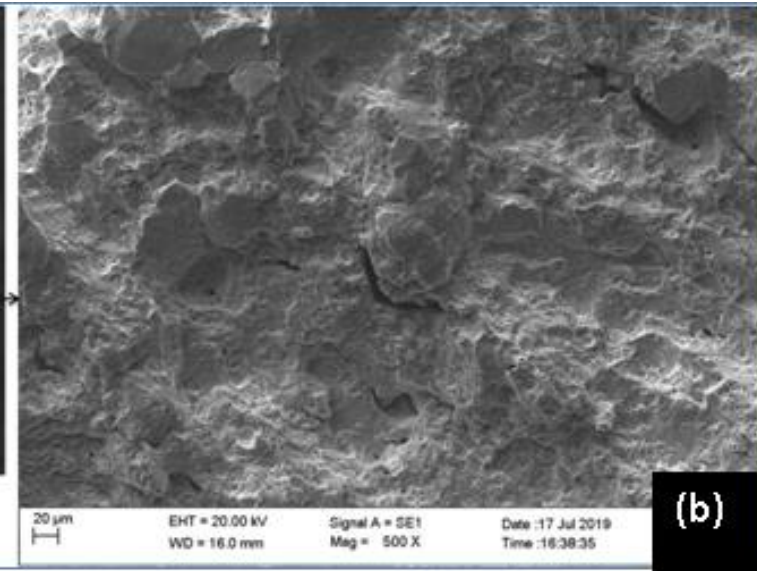

Fig. 8: SEM fractographs of failed bolt head in Branson cleaned condition. 

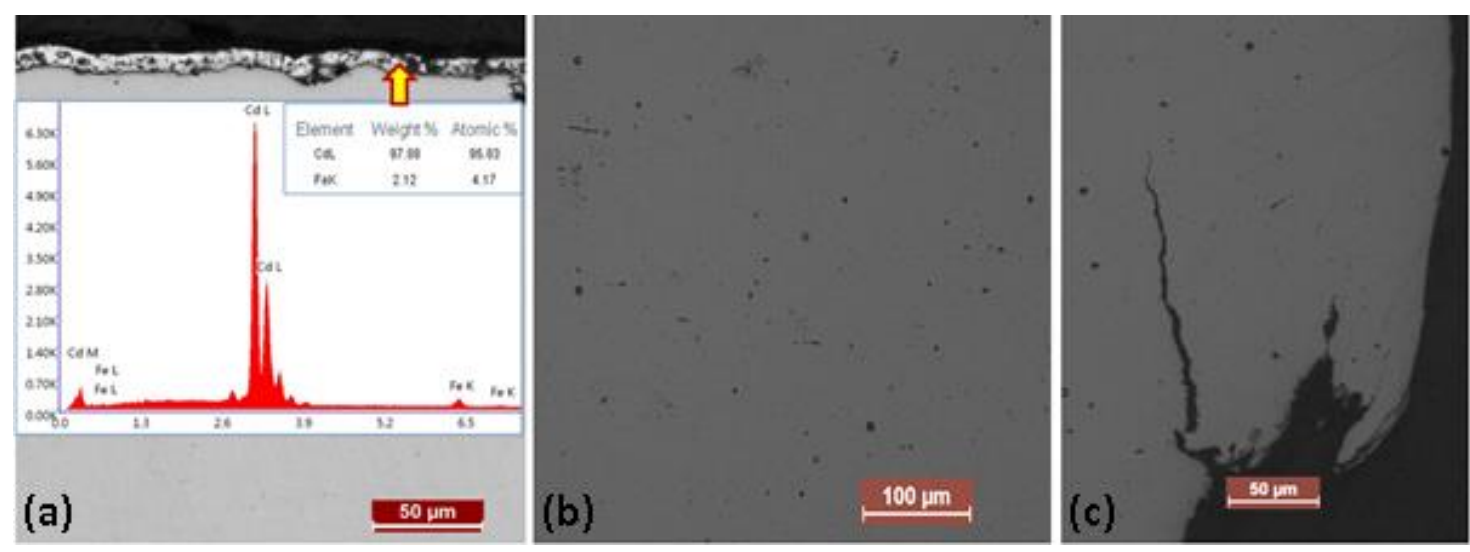

Fig. 9: Optical micrographs of the failed sample in un-etched condition: (a) presence of cadmium coating at the surface as supported by SEM EDS pattern, (b) oxides and sulphide stringers in microstructure and (c) cracks starting from the fracture surface.

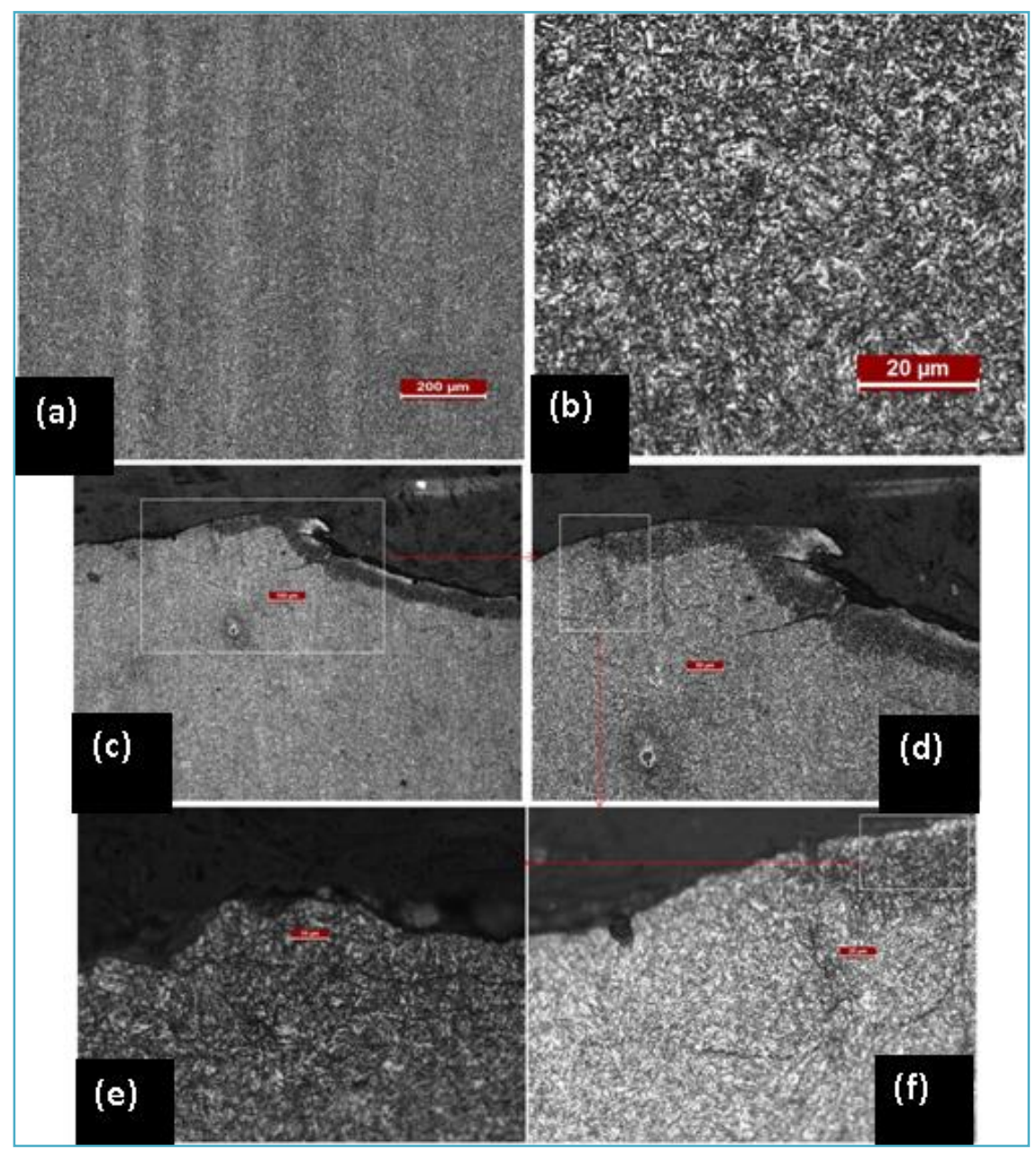

Fig. 10: Optical micrographs of the failed sample: (a) banding and (b-f) tempered martensite structure along with few peripheral cracks. Etchant: 3\% nital. 


\subsection{Hardness}

An average hardness value for both the components is approximately $340 \mathrm{HV}$ under $20 \mathrm{~kg}$ load.

\subsection{Chemical Composition}

Chemical compositions of the trace elements and bulk material are given in Tables 1 and 2, respectively. It reveals the presence of $\mathrm{C}$ in medium range along with $\mathrm{Si}, \mathrm{Cr}$ and $\mathrm{Ni}$ as major alloying elements, while the base is $\mathrm{Fe}$.

Table 1: Analyzed trace elements in the bolt material

\begin{tabular}{|c|c|c|c|}
\hline Elements & C & S & H \\
\hline Composition, wt.\% (standard deviation) & $0.45(0.01)$ & $0.011(0.002)$ & $0.0007(0.0001)$ \\
\hline
\end{tabular}

Table 2: Analyzed major elements in the bolt material

\begin{tabular}{|c|c|c|c|c|c|c|c|c|}
\hline Elements & $\mathbf{P}$ & $\mathrm{Ti}$ & $\mathrm{Al}$ & $\mathrm{Si}$ & $\mathrm{Mn}$ & $\mathrm{Cr}$ & $\mathrm{Mo}$ & $\mathrm{Fe}$ \\
\hline Composition, wt\% & 0.0025 & 0.002 & 0.08 & 0.60 & 0.54 & 0.67 & 0.57 & Bal. \\
(standard deviation) & $\begin{array}{c}0.0002 \\
\text { ) }\end{array}$ & $\begin{array}{c}0.0002 \\
\text { ) }\end{array}$ & $(0.002)$ & $(0.002)$ & $(0.01)$ & $(0.02)$ & $(0.04)$ & \\
\hline
\end{tabular}

\section{DISCUSSIONS}

\subsection{Fracture Mechanism}

The fracture feature shows multiple initiation points such as A and B. Two different fatigue crack fronts starting from points $A$ and $B$ have propagated towards each other. This is usually observed during a bending fatigue phenomenon. The crack fronts coincide with each other along line $L-L^{\prime}$. At the same time, another crack front of fast fracture with typical Chevron pattern originated at point $B$ and advanced in another (separate) direction. Each of the above crack fronts seem to have proceeded independently, as is clear from the propagation paths $[4,5]$. Therefore, both the bending fatigue and fast fracture have contributed to the present failure independently, while the failure mechanisms are different to each other. Interestingly, the contributions of both the failure mechanisms as described above appear to be approximately equal based on the area of fracture surface covered i.e. 50\% each.

\subsection{Presence of Cadmium: Its Source and Implication}

Cadmium is found on the whole fracture surface. However, its presence in larger amount was remarkable in plain region having Chevron pattern as compared to that in bending fatigued region. This has been confirmed visually as well as under SEM and also verified by the EDS analysis. Presence of larger amount of cadmium on the fast fracture region indicates that the intake of cadmium has occurred during and / or subsequent to the application of cadmium plating onto the component. It is important to mention here that the cracks are already present in component and these cracks have facilitated the access of cadmium inside the material. Manifestation of these pre-existing cracks in the present case is in form of a fast fracture with chevron pattern. This is also supported by the presence of ample of secondary cracks observed on fractographs (Figs. 2 and 8) as well as on metallographic samples (Fig. 9) containing the fracture surface.

\subsection{Presence of Corrosion: Its Possibility and Contribution to two independent fracture mechanisms}

Fast fracture region in acetone cleaned condition contains significant amount of cadmium and oxygen along with sulphur, chlorine, sodium, potassium and calcium (Figs. 3 and 4). Another location of the same fracture region contains cadmium and iron with significant amount of oxygen and small quantity of calcium (Figs. 5 and 6). On the other hand, fatigued region is found to contain either almost pure cadmium or cadmium with oxygen (Fig. 7). Elements such as sulphur, chlorine, sodium, magnesium and calcium are often found to be there along with cadmium and oxygen. These findings indicate that the corrosion of cadmium plating may have happened, although the evidence of bolt corrosion is rather not sufficient.

Indication of corrosion of virgin bolt material is rarely typified by the presence of appreciable amount of Fe in cadmium-oxygen rich products on the fracture surfaces [5]. Therefore, it is possible that the corrosion of the cadmium plating has occurred and it has happened on the pre-existing fast fracture region. Corroding fluid containing chlorine, sulphur and few above mentioned alkaline earth metals seems to have come in touch with the pre-cracked region. It is worth mentioning that all the said elements might have come from the various sources such as environment (like chlorine), rock salts (like sodium, calcium, magnesium etc.) present in a runway or in environment, aviation fuel residues and contaminants (like sulphur) [6-8], thus ruling out the possibility of corrosion. Moreover, it is also to be noted that there no presence of mud-cracks indicating the corrosion was detected in the present case. However, enrichment of oxygen along with iron on few locations on the fracture surface points out to the presence of corrosion, how insignificant it may be. 
On the other hand, rare presence of oxygen-rich products on fatigued region indicates that corrosion did not happen in that region. However, it is possible that the corrosion debris of fast fracture region got entered into the fatigued region by some means, subsequent to the failure of fatigued region.

It is quite obvious, based on these evidences that the corrosion did not occur on the cadmium plated bolt surface causing its failure. Thus, corrosion did not contribute at all to the present failure. It is rather a post-cracking event in the fast fracture region and did not contribute to the bending fatigue failure of the remaining cross-section directly. However, there is a finite chance of the said corrosion to have induced the reversed bending fatigue cracking phenomenon at point B (Fig. 2b). Nevertheless, there is no trace of corrosion debris, although a crack is found (Fig. $5 b)$, similar to that is observed at location $A$ also. This is further corroborated by the presence of numerous cracks on the fracture surfaces as well as on metallographically polished samples.

\subsection{Presence of Bending Type of Service Load}

Existence of bending type of load is well proved considering: (i) visually observed bending of the failed component, (ii) presence of bending fatigue on the fracture surface and (iii) presence of chevron pattern.

\subsection{Construction Material: Its Identity and Suitability}

Material looks to be a chromium-molybdenum grade steel closely matching to that of ASTM grade 16 governed by the specification A194/A194M [2, 3]. The as-desired hardness range for this material has been specified to be 250$330 \mathrm{HV}$. However, the obtained hardness value of $340 \mathrm{HV}$ in the present case is significantly higher than the asdesired one. This raises the suitability of the material in its current form. It may be noted that there are multiple initiation sites of the fracture surface. Also, there are secondary cracks in each of the initiation sites (as indicated in area A, Figs. 2d and 5b). Interestingly, cracks are found even on the section with fracture surface having Chevron mark. There are ample of such evidences wherein secondary cracks are observed on Branson cleaned (virgin) fracture surface (Fig. 8), thus ruling out the possibility of mud-cracking or cracks present on cadmium-coated surface. The secondary cracks are also observed on the metallographic samples taken across the fracture surface. In other words, material seems to be in a high-hardened (than the as-specified and desired) or embrittled state due to improper heat treatment or any other processing step.

A schematic of the probable causes of failure of the bolt is presented in Figure 11. This guides and explains the thought process involved in reaching to the conclusion in the present case [5]. This looks to be a case of material failure arising out of the interior and / or surface defects due to the embrittling effect coming from the associated processes employed for manufacturing the component. The non-suitability of the presently used material is quite well proven here through observation of the obtained hardness values, as mentioned earlier. All other possibilities (as presented in Fig. 11) are initially listed and rule out one by one and finally conclusion is arrived based on the visual and microscopic observations and very importantly, supported by the background information received from the user.

\section{CONCLUSIONS}

The following conclusions can be drawn from the present investigation:

1. Bolt has failed by a combined action of bending induced fast fracture and fatigue phenomena. These are two independent phenomena and each covers approximately $50 \%$ of the fractured area.

2. Pre-existing cracks have initiated the present failure, firstly as Chevron mark followed by inducing bending fatigue.

3. Brittleness of the construction material has resulted in the present failure.

4. Cracks of considerable dimensions are present in the material prior to the introduction of cadmium plating and Chevron mark is immediate manifestation.

\section{ACKNOWLEDGEMENT}

The authors are grateful to the DRDO for funding the present work. They are also thankful to Dr. $G$ Madhusudhan Reddy, Outstanding Scientist and Director of DMRL for his constant encouragement to work on the present field.

\section{REFERENCE}

1. Steel fasteners for the temperature range between $-50^{\circ} \mathrm{C}$ and $+150^{\circ} \mathrm{C}$, https://www.wuerth-industrie.com, last accessed on 20.01.2021.

2. ASTM A - 194: Standard Specification for Carbon and Alloy Steel Nuts for Bolts for High-Pressure and HighTemperature Service, last accessed on 20.01.2021.

3. ASTM A - 320: Standard Specification for Alloy Steel and Stainless Steel Bolting Materials for Low Temperature Service, last accessed on 20.01.2021.

4. Metal Fatigue: Theory and Design, Ed. A. F. Madayag, pp. 3-5, 1968.

5. ASM Metals Handbook Vol 11: Failure Analysis and Prevention, edited by W. T. Becker and R. J. Shipley, ASM International, 2002, Metals park, Ohio. 
6. Pszenny. A. A. P., Keene. W. C., Jacob. D. J., Fan. S., Maben. J. R., Zetwo. M. P., Springer-Young. M., and Galloway. J. N., Evidence of inorganic chlorine gases other than hydrogen chloride in marine surface air, Geophysical Research Letter, 20(8) 1993, pp. 699-702.

7. Titler, R. V., Chemical analysis of major constituents and trace contaminants of rock salt, Rock Salt Paper final 052711.pdf, last accessed on 20.01.2021.

8. Groysman, A., Corrosion in systems for storage and transportation of petroleum products, NACE International Corrosion Conference Series 2015, Springer.

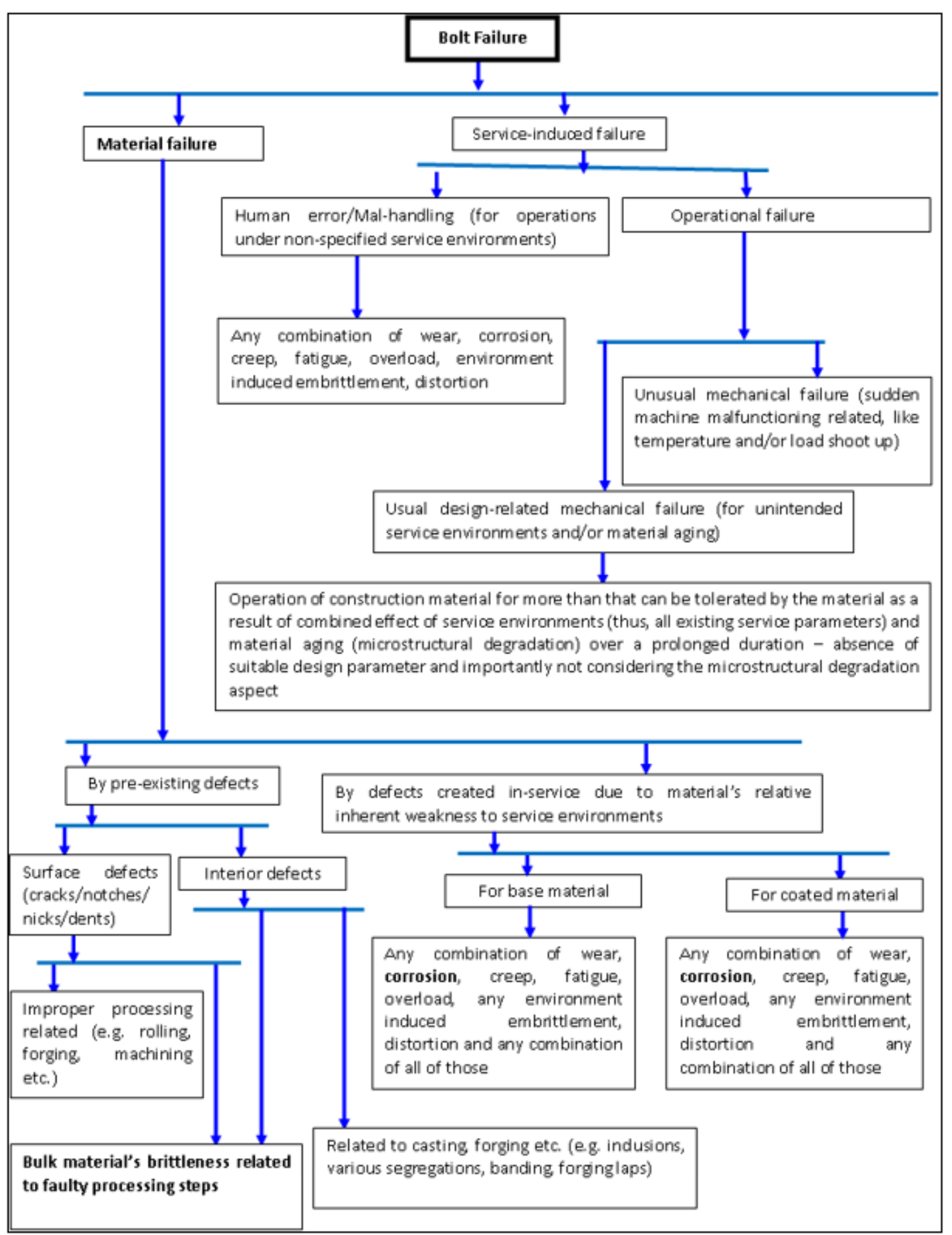

Figure 11: Proposed schematic sequential representation of the probable causes of failure of the bolt facilitating to arrive at conclusion in present failure analysis case (bold captions indicate the concluded most probable cause(s)). 